\begin{tabular}{rll}
\hline 45$)$ & $\begin{array}{l}\text { Jurnal Teknologi Kimia Unimal } \\
\text { http://ojs.unimal.ac.id/index.php/jtk }\end{array}$ & $\begin{array}{l}\text { Teknologi } \\
\text { Kimia } \\
\text { Unimal }\end{array}$ \\
\hline \hline
\end{tabular}

\title{
Pengaruh Waktu Ekstraksi Daun Jeruk Nipis (Citrus aurantifolia) Menggunakan Pelarut n-Heksana terhadap Rendemen Minyak
}

\author{
${ }^{\mathbf{1}}$ Nasrun Ibrahim ${ }^{*}$, ${ }^{1}$ Jalaluddin, ${ }^{1}$ Nurul Rahmah \\ ${ }^{1}$ Jurusan Teknik Kimia, Fakultas Teknik, Universitas Malikussaleh \\ Jl. Batam No. 1, Bukit Indah, Lhokseumawe 24351 \\ ${ }^{*}$ Email: nasrun@unimal.ac.id
}

\begin{abstract}
Abstrak
Indonesia memiliki sumber daya alam yang kaya akan minyak atsiri. Salah satu sumber daya alam yang potensial adalah jeruk nipis yang dapat dimanfaatkan sebagai flavor dalam makanan. Pengambilan minyak atsiri daun jeruk nipis menggunakan metode ekstraksi pelarut mudah menguap.Tujuan penelitian adalah untuk mengetahui pengaruh waktu ekstraksi terhadap rendemen, indek bias, dan densitas minyak atsiri yang dihasilkan. Ekstraksi minyak daun jeruk nipis dengan pelarut n-heksana menggunakan ekstraktor soxhlet. Daun jeruk nipis yang tua yang sudah dibersihkan, dipotong kecilkecil dan dibungkus dengan kertas saring dan dimasukkan dalam soxhlet. Pelarut n-heksana sebanyak $200 \mathrm{ml}$ dimasukkan dalam labu alas bulat ekstraktor yang dilengkapi pendingin. Ekstraksi dilakukan pada suhu dan waktu tertentu tergantung dari jenis pelarut yang digunakan, sampai dihasilkan warna pelarut kembali seperti semula. Selanjutnya filtrat didistilasi untuk dimurnikan, sehingga diperoleh minyak daun jeruk nipis terpisah dari pelarutnya. Minyak atsiri kemudian dilakukan uji rendemen, indek bias, dan densitas yang terkandung dalam minyak atsiri. Hasil penelitian diperoleh ekstraksi daun jeruk nipis dengan pelarut $n$-heksan, rendemen yang tertinggi diporoleh pada berat sampel 200 gram dengan waktu ekstraksi 180 menit yaitu 3,11\%. Indek bias minyak tertinggi juga diperoleh pada berat sampel 200 gram dengan waktu ekstraksi 180 menit yaitu 1,47, sedangkan densitas minyak atsiri dari daun jeruk nipis diperoleh 0,79 $\mathrm{gr} / \mathrm{ml}$.
\end{abstract}

Kata kunci: minyak atsiri, daun jeruk nipis, ekstraksi, n-heksana 


\begin{abstract}
Indonesia has natural resources that are rich in essential oils. One potential natural resource is lime which can be used as flavor in food. The extraction of lime leaf essential oil using volatile solvent extraction method. The aim of the study was to determine the effect of extraction time on yield, refractive index, and density of essential oils produced. Extraction of lime leaf oil with n-hexane solvent using soxhlet extractors. The old lime leaves that have been cleaned, cut into small pieces and wrapped in filter paper and put in soxhlet. $200 \mathrm{ml} \mathrm{n}$ hexane solvent is inserted in an extractor round bottom flask equipped with coolant. Extraction is carried out at a certain temperature and time depending on the type of solvent used, until the solvent color is returned as before. Then the filtrate was distilled to be purified, so that lime leaf oil was obtained separately from the solvent. Essential oils are then tested for yield, refractive index, and density contained in essential oils. The results of the study were extraction of lime leaves with n-hexane solvent, the highest yield obtained at a sample weight of 200 grams with an extraction time of 180 minutes which was $3.11 \%$. The highest oil refractive index was also obtained at a sample weight of 200 grams with an extraction time of 180 minutes which was 1.47 , while the density of essential oil from lime leaves was 0.79 $\mathrm{gr} / \mathrm{ml}$.
\end{abstract}

Keywords: essential oil, lime leaf, extraction, n-heksana

\title{
1. PENDAHULUAN
}

Selama ini kita mengetahui bahwa jeruk nipis adalah salah satu jenis buah yang banyak ditemui di Indonesia. Tanaman jeruk nipis akan tumbuh dengan baik dilokasi yang mendapat cukup sinar matahari. Jeruk nipis mengandung sari asam yang tinggi. Buah jeruk nipis banyak mengandung vitamin $\mathrm{C}$, asam sitrat, asam amino, (triptofan, lisin), minyak atsiri (sitral, limonene, felanden, lemon kamfer, kadinen, dan nidehida), glikolisa, asam sitrun, belerang dan vitamin B (tiamin). Buah jeruk nipis terkenal sebagai buah yang berkhasiat menyembuhkan batuk, mengurangi dahak, menyembuhkan panas dalam, merawat kecantikan wajah serta menghilangkan jerawat (Tjitrosoepomo, 2003a). 
Minyak atsiri umumnya merupakan komponen pemberi bau yang khas, atau disebut minyak eteris, minyak menguap atau essential oil yaitu bahan aromatis alam yang berasal dari tumbuhan. Ciri minyak atsiri antara lain mudah menguap pada suhu kamar tanpa mengalami dekomposisi, mempunyai rasa getir, berbau wangi sesuai tanaman penghasilnya dan bersifat larut dalam pelarut organik dan tidak larut dalam air (Tjitrosoepomo, 2003b).

Minyak atsiri memiliki bau mirip tanaman asalnya yang diambil dari bagian-bagian tanaman seperti daun, buah, biji, bunga, akar, rimpang, kulit kayu, bahkan seluruh bagian tanaman. Setiap tahun konsumsi minyak atsiri dunia beserta turunannya naik sekitar $8-10 \%$. Hal itu tidak hanya terjadi di Indonesia, salah satu sumber minyak atsiri dunia, namun berlaku pula di negara-negara produsen lain seperti India, Thailand, dan Haiti. Pemicu kenaikan itu antara lain meningkatnya kebutuhan minyak atsiri untuk industri parfum, kosmetik, dan kesehatan. Selain itu produk-produk olahan minyak atsiri belum dapat digantikan oleh bahan sintetis (Astrarini, 2009).

Pemikiran untuk memproduksi jenis minyak atsiri baru yang diduga bernilai komersial tinggi dirasa perlu untuk memberikan nuansa baru terhadap dunia peminyak atsirian. Perkembangan teknologi pengolahan minyak atsiri di beberapa negara maju menjadi salah satu faktor pendukung yang dapat memberikan nilai tambah terhadap komoditas itu sendiri. Dari sekian ratus minyak atsiri yang diperdagangkan di dunia, tanaman dari jenis jeruk-jerukan (genus Citrus) adalah yang paling banyak digunakan sebagai bahan baku minyak atsiri. Dilihat dari banyaknya kegunaan jeruk nipis maka perlu diadakannya penelitian untuk mengetahui lebih lanjut tentang minyak atsiri yang terkandung dalam daun jeruk nipis.

Daun jeruk nipis sejauh ini belum dimanfaatkan secara maksimal. Berdasarkan hipotesa bahwa daun jeruk nipis dapat dibuat atau diolah sehingga memiliki nilai tambah yang tinggi yaitu diolah menjadi minyak atsiri yang dapat dijadikan untuk berbagai manfaat diantaranya dapat dijadikan sebagai flavoring 
agent dalam bahan pangan atau minuman, antiseptik obat-obatan, pembuatan kosmetik, parfum, pencampur rokok kretek, aroma terapi, obat gosok, dan lainlain. Penelitian ini mencoba untuk mengkaji secara langsung minyak atsiri yang dihasilkan dari daun jeruk nipis. Tujuan penelitian adalah untuk mengetahui pengaruh waktu ekstraksi terhadap rendemen minyak, indek bias minyak, dan densitas minyak atsiri yang didapatkan dari daun jeruk nipis.

\section{Bahan dan Metode}

\subsection{Alat dan Bahan}

Sebelum melakukan penelitian, alat dan bahan harus dipersiapkan terlebih dahulu. Alat dan bahan yang digunakan adalah seperangkat alat ekstraksi-distilasi, beaker glass, Erlenmeyer, piknometer, refraktometer, botol sampel, pipet ukur, pisau/gunting, neraca analitik, kertas saring, daun jeruk nipis, dan n-heksan.

\subsection{Variabel Penelitian}

Variabel tetap dalam penelitian ini adalah volume pelarut $200 \mathrm{ml}$ dan temperatur ekstraksi $69^{\circ} \mathrm{C}$. Adapun variabel bebas adalah waktu ekstraksi, 60, 100, 140, dan 180 menit serta berat sampel 100, 150, dan 200 gram.

Variabel terikatnya adalah rendemen minyak, densitas, dan indek bias minyak atsiri.

\subsection{Metode}

Adapun langkah-langkah dalam melakukan penelitian ini adalah persiapan bahan baku, ekstraksi, destilasi, dan analisis. Daun jeruk nipis tua dibersikan dan kemudian dirajang/dipotong kecil-kecil untuk diekstraksi dengan alat soxhlet dengan perlakuan sesuai dengan variabel. Setelah mencapai waktu yang ditentukan proses ekstraksi dihentikan, dan dilanjutkan dengan proses distilasi untuk memisahkan antara pelarut dengan minyak atsiri yang didapat. Setelah didapatkan minyak daun jeruk nipis, minyak tersebut dimasukkan ke dalam botol sampel, kemudian dianalisa seperti analisa rendemen, analisa densitas, dan indek bias. 


\section{Hasil dan Diskusi}

Pada ekstraksi minyak daun jeruk nipis (Citrus Aurantifolia) dengan menggunakan pelarut n-heksan meliputi beberapa tahapan yaitu: perlakuan bahan, proses ekstraksi minyak dari daun jeruk nipis, proses pemurnian (distilasi) dan hasil produknya. Pada proses perlakuan bahan, bahan yang digunakan adalah daun jeruk nipis yang tua, digunakan bahan yang tua karena kandungan minyak atsirinya lebih banyak dari pada bahan yang muda serta mengandung kadar air yang rendah. Bahan kemudian dirajang/dipotong kecil-kecil, proses pengecilan ukuran ini bertujuan agar kelenjar minyak dapat terbuka sebanyak mungkin sehingga pada proses ekstraksi laju penguapan minyak atsiri dari bahan menjadi cukup cepat (Guenther, 1987a).

Ektraksi daun jeruk nipis menggunakan pelarut n-heksan sebagai pelarut dikarenakan n-heksan bersifat stabil dan mudah menguap, selektif dalam melarutkan zat, mengekstrak sejumlah kecil lilin serta dapat mengekstrak zat pewangi dalam jumlah besar. Proses pemurnian minyak bertujuan untuk memisahkan minyak atsiri dengan pelarut sehingga dihasilkan minyak atsiri yang absolute (Guenther, 1987b).

\subsection{Pengaruh Waktu Ekstraksi Terhadap Rendemen Minyak Atsiri}

Pengaruh waktu ekstraksi terhadap rendemen minyak yang diperoleh dari masing-masing berat sampel dengan pelarut n-heksan pada waktu ekstraksi 60 menit, 100 menit, 140 menit, dan 180 menit dapat dilihat pada Gambar 1.

Lamanya waktu ekstraksi akan mempermudah penetrasi pelarut dalam sampel. Kelarutan minyak atsiri berjalan dengan perlahan sebanding dengan lamanya waktu ektraksi. Akan tetapi, setelah mencapai waktu optimum maka jumlah minyak mengalami penurunan. Hal ini terjadi karena jumlah minyak pada sampel terbatas, sehingga walaupun waktu ekstraksi diperpanjang lagi, minyak yang ada dalam sampel sudah habis. 


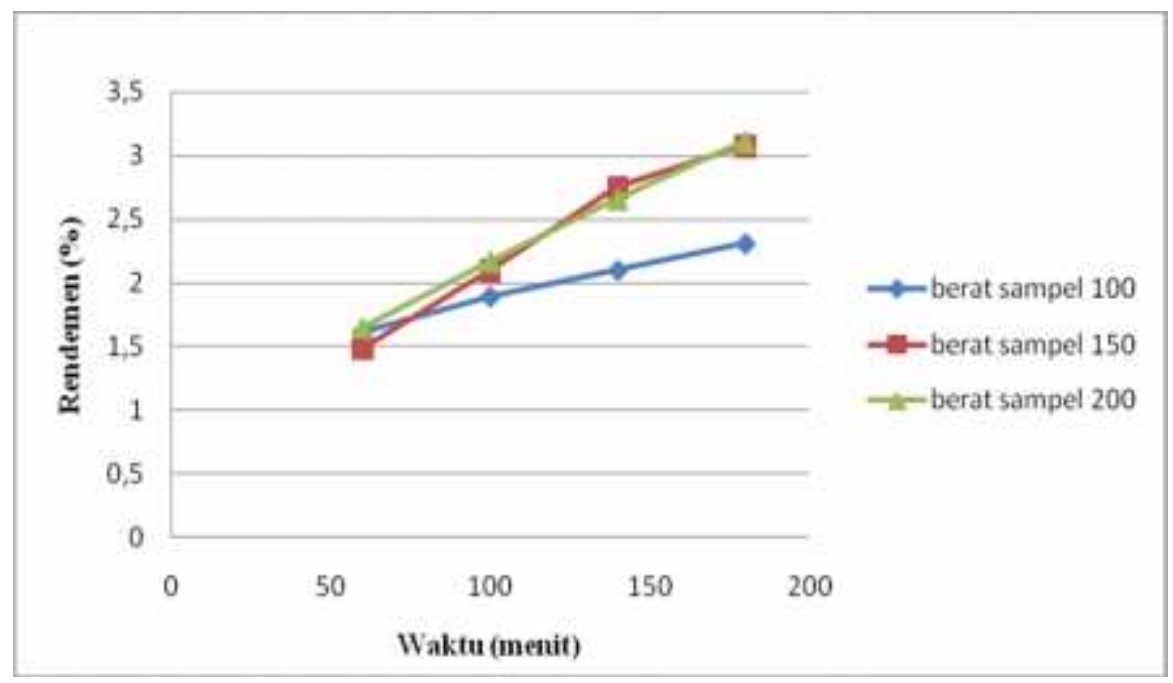

Gambar 1 Pengaruh Waktu Ekstraksi Terhadap Rendemen Minyak Atsiri

Gambar 1 menunjukkan rendemen dipengaruhi oleh waktu ekstraksi. Semakin lama waktu ekstraksi maka rendemen minyak yang di dapatkan juga semakin besar. Hal ini bisa disebabkan pengontakan pelarut dengan sampel yang diekstrak semakin lama, maka sirkulasi yang terjadi juga banyak sehingga minyak yang terikut dalam pelarut juga semakin banyak. Rendemen minyak yang tertinggi diperoleh pada berat sampel 200 gram dengan waktu ekstraksi 180 menit, rendemen yang diperoleh adalah $3,115 \%$.

\subsection{Pengaruh Waktu Ekstraksi Terhadap Indek Bias Minyak}

Pengaruh waktu ekstraksi terhadap indek bias yang diperoleh dari pengujian terhadap masing-masing berat sampel dengan menggunakan pelarut nheksan serta dengan waktu ekstraksi yang bervariasi dapat dilihat pada Gambar 2. Pengujian indek bias bertujuan untuk mengetahui kemurnian minyak yang dihasilkan. Indek bias dipengaruhi oleh kandungan air dalam minyak. Semakin banyak kandungan air dalam minyak maka semakin kecil nilai indek biasnya. Hal ini disebabkan sifat air yang mudah untuk membiaskan cahaya yang datang (Corner, 2007).

Minyak atsiri dengan indek biasnya besar lebih bagus dibandingkan minyak atsiri dengan indek biasnya kecil (Guenther, 1987c). Tingginya nilai indek bias dipengaruhi oleh waktu ekstraksi, dimana semakin lama waktu ekstraksi 
semakin tinggi nilai indek biasnya. Hal ini dikarenakan pengikatan antara pelarut dengan zat terlarut lebih lama dan sempurna sehingga semakin banyak komponen yang ikut tersuling dan menghasilkan minyak yang lebih murni (Anonim, 1995a).

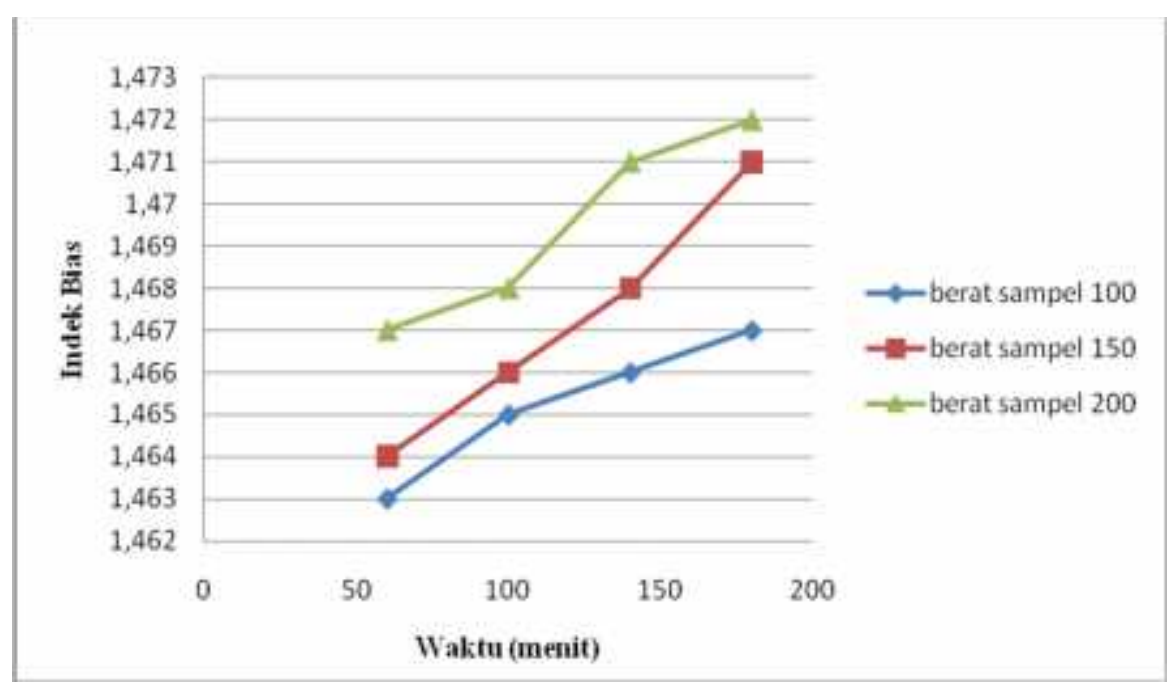

Gambar 2 Pengaruh Waktu Ekstraksi Terhadap Indek Bias Minyak

Indek bias minyak atsiri berhubungan erat dengan komponen-komponen yang tersusun dalam minyak atsiri yang dihasilkan. Sama halnya dengan berat jenis dimana komponen penyusun minyak atsiri dapat mempengaruhi nilai indek biasnya. Semakin banyak komponen berantai panjang/komponen bergugus oksigen ikut tersuling, maka kerapatan minyak atsiri akan bertambah sehingga cahaya yang datang akan lebih sukar untuk dibiaskan. Hal ini menyebabkan indek bias minyak semakin besar (Anonim, 1995b).

Gambar 2 memperlihatkan pengaruh waktu ekstraksi terhadap indek bias minyak, indek bias semakin tinggi dengan waktu ekstraksi yang semakin lama, ini sesuai dengan teori yang mengatakan tingginya nilai indeks bias dipengaruhi oleh waktu ekstraksi, dimana semakin lama waktu ekstraksi semakin tinggi nilai indek biasnya. Hal ini dikarenakan pengikatan antara pelarut dengan zat terlarut lebih lama dan sempurna sehingga semakin banyak komponen yang ikut tersuling. Nilai 
indek bias tertinggi diperoleh pada berat sampel 200 gram dengan waktu ekstraksi 180 menit yang menghasilkan nilai indek bias 1,472 .

\subsection{Pengujian Densitas (Berat Jenis) Minyak}

Berat jenis merupakan salah satu kriteria penting dalam menentukan kualitas mutu minyak atsiri. Menurut Nugraheni (2012), pada umumnya berat jenis minyak atsiri pada suhu $25^{\circ} \mathrm{C}$ berkisar antara 0,696-1,188 $\mathrm{g} / \mathrm{ml}$. Dan umumnya berat jenis minyak atsiri lebih kecil dari berat jenis air (1 gr/ml). Berat jenis juga sering dihubungkan dengan fraksi berat dari komponen yang terkandung pada minyak atsiri tersebut. Berat jenis suatu minyak dipengaruhi oleh jenis dan jumlah komponen senyawa yang terkandung dalam minyak.

Menurut Reineccius (1994) berat jenis merupakan fungsi dari komponenkomponen penyusunnya dan proporsinya masing-masing. Tiap-tiap komponen mempunyai berat jenis yang berbeda beda. Semakin tinggi konsentrasi komponen minyak maka semakin tinggi pula berat jenisnya.

Hasil penelitian menunjukkan bahwa densitas minyak atsiri dari daun jeruk nipis yang didapat adalah 0,7948 gr/ml, masih sesuai dengan penelitian Nugraheni (2012) yang mengatakan berat jenis minyak atsiri pada suhu $25^{\circ} \mathrm{C}$ berkisar antara 0,696-1,188 g/ml. Pada umumnya berat jenis minyak atsiri lebih kecil dari berat jenis air $(1 \mathrm{gr} / \mathrm{ml})$.

\section{Penutup}

\subsection{Kesimpulan}

Berdasarkan hasil penelitian maka dapat disimpulkan bahwa rendemen minyak dipengaruhi oleh waktu ekstraksi, di mana semakin lama waktu ekstraksi maka minyak yang didapatkan juga semakin meningkat. Rendemen minyak tertinggi diperoleh pada berat sampel 200 gram dengan waktu ekstraksi 180 menit yaitu 3,115\%. Indek bias minyak yang didapatkan semakin tinggi jika waktu ekstraksi semakin lama, hal ini dikarenakan oleh pengikatan antara pelarut dengan zat terlarut lebih lama dan sempurna sehingga semakin banyak komponen yang 
tersuling. Indek bias tertinggi diperoleh pada berat sampel 200 gram dan dengan waktu ekstraksi 180 menit yaitu 1,472. Densitas rata-rata minyak atsiri dari daun jeruk nipis adalah $0.7948 \mathrm{gr} / \mathrm{ml}$.

\subsection{Saran}

Hendaknya dilakukan penelitian lanjutan dengan memvariasikan pelarut untuk mengetahui jenis pelarut yang baik dalam proses ekstraksi minyak daun jeruk nipis dan dilakukan pengeringan bahan serta pengecilan ukuran bahan dengan cara dihancurkan dengan blender dan diayak menggunakan ukuran mesh yang kecil untuk mengetahui jenis bahan mana yang banyak memperoleh rendemen, indek bias dan densitas minyak yang tinggi.

\section{Daftar Pustaka}

Astarini, F. P.N; Burhan, P. Y. R; Zetra, Y., Minyak Atsiri Dari Kulit Buah Citrus Grandis, Citrus Aurantium x (L), dan Citrus Aurantifolia (RUTACEAE) Sebagai Senyawa Anti Bakteri dan Insetisida, Prosiding Skripsi, Dipublikasikan, Surabaya: FMIPA ITS, 2009.

Nugraheni, K.S., Pengaruh Perlakuan Pendahuluan dan Metode Destilasi Terhadap Karakteristik Mutu Minyak Atsiri Daun Kayu Manis, Fakultas Pertanian. Universitas Sebelas Maret Surakarta, Surakarta, 2012.

Reineccius, G., Flavor Chemistri, Di dalam: Hidayat, F. K., Ekstraksi Minyak Atsiri Dari Daun Jeruk Purut (Citrus hystrix DC) pada Skala Pilot-Plant, Sripsi, Jurusan Teknologi Pangan dan Gizi Fakultas Teknologi Pertanian Institut Pertanian Bogor, Bogor (1994).

Tjitrosoepomo, Gembong., Morfologi Tumbuhan, Yogyakarta: Gajah Mada University Press. 